\title{
LA REVISTA LA VIDA LITERARIA (1899) COMO REFLEJO DE UNA NUEVA ESTÉTICA FINISECULAR
}

\author{
Diana Muela Bermejo \\ dmuela@unizar.es \\ Universidad de Zaragoza
}

\section{Resumen}

El trabajo estudia la revista La Vida Literaria, publicada en 1899 con un total de treinta y un números, atendiendo a las ideas estéticas que allí se divulgaron, especialmente el Modernismo y la literatura de ensueño y a su carácter importador, juvenil y europeísta. Se analizará su evolución relacionada con el periodo de dirección de Jacinto Benavente y la segunda etapa, sin el dramaturgo madrileño, de carácter menos renovador, y con especial atención a los escritores de relevancia que publicaron en sus números.

Palabras clave: Revista literaria, Modernismo, literatura finisecular, literatura de ensueño, Jacinto Benavente.

\begin{abstract}
This work analyzes the magazine La Vida Literaria, which published thirty one numbers in 1899. It studies the aesthetic ideas, her importing role and also her position as a support of young writers, both in Spain and foreign countries. The development of La Vida Literaria is especially important because of the differences between the numbers managed by Jacinto Benavente and the rest, less reformist and more traditional. It also examines the texts of the most important writers who appeared thourghout her numbers.
\end{abstract}

Keywords: Literary magazine, Modernism, Fin-de-siècle literature, dream's literature, Jacinto Benavente. 
La Vida Literaria se publicó por primera vez en Madrid, el 7 de enero de 1899. Surgió como suplemento de Madrid Cómico, revista dirigida por Sinesio Delgado primero, Ruiz de Velasco y Clarín después y por el propio Benavente durante cuatro meses en 1898. En los últimos años del siglo XIX, Madrid Cómico atravesaba una etapa de transición: Sinesio Delgado la había convertido en un icono satírico de la Restauración y Ruiz de Velasco y Clarín intentaron rejuvenecerla (Versteeg, 2009: 427). Sin embargo, en el último número de la revista (31-XII-1898) se comunicó a los lectores que pasaría a publicarse de forma quincenal y se regalaría a los suscriptores de La Vida Literaria, y Madrid Cómico terminó desapareciendo dos meses después de que aquella dejara de publicarse (Versteeg, 2009: 434).

La Vida Literaria se creó con la voluntad de dar cabida a la juventud atraída por la renovación del anquilosado panorama de las letras españolas, tanto en sus textos narrativos como en otros de carácter más teatral. Sin embargo, el primer número anunciaba que los autores jóvenes se verían acompañados por otros ya consagrados y, también, por nuevas figuras del horizonte hispanoamericano, muchas de ellas desconocidas por el público español; de ese modo, la revista fue adquiriendo un carácter internacional que abarcaría letras europeas e hispanoamericanas.

El precio por número era de veinte céntimos (excepto el primero, «Almanaque», que costaba cincuenta); la suscripción trimestral en Madrid 2'50 pesetas, semestral 5 pesetas y anual 9 pesetas. En provincias, Portugal y el extranjero, la trimestral costaba 3 pesetas, la semestral 6, la anual para provincias y para Portugal $11 \mathrm{y}$, por último, 17 pesetas para ultramar y para el extranjero. Con cada número de la revista se regalaba el correspondiente de Madrid Cómico y también un suplemento quincenal titulado El Desnudo en el Arte: láminas sueltas en papel mate que completarían un álbum con reproducciones de obras de los pintores más afamados, antiguos y modernos.

El administrador propietario fue Bernardo Rodríguez Serra y su primer director Jacinto Benavente, quien mantuvo la dirección de la revista durante sus once primeros números, del 7 de enero al 18 de marzo de 1899. Sin embargo, en una entrevista con Enrique González Fiol, publicada en su libro Domadores del éxito: confesiones de su vida y de su obra, Benavente afirmó que él apenas había dirigido dos o tres números de la revista:

Dirigí La Vida Literaria durante la publicación de dos o tres números nada más; cuando Clarín dejó de dirigirla [...] Allí pasaba que el director sólo tenía la revista para su fin particular: para colocar en Cataluña y América los libros que editaba. Con objeto de conseguir reclamos para sus publicaciones, admitía originales de gentes que... Con decirle que hasta corredores de libros firmaron en la revista artículos y poesías estupendas... Naturalmente, 
a «Clarín» le molestaba que en un periódico en que él figuraba como director se publicasen aquellas puerilidades. Un día, tanto por decoro como por ataques que le dirigieron desde no sé qué periódico, escribió una posdata en un artículo suyo, diciendo: «Muchos corresponsales y amigos míos me preguntan si apruebo yo todos los originales que aparecen en La Vida Literaria. Yo no respondo más que de lo que lleva mi firma» (González Fiol, 1915: 52).

No queda constancia de que Clarín dirigiera en ningún momento La Vida Literaria. Probablemente se trate de una confusión con Madrid Cómico, donde sí se produjo esa sucesión a partir de septiembre de 1898, cuando Clarín dejó la dirección del periódico. Sin embargo, Benavente añade después en dicha entrevista: «Me cansé en seguida. En La Vida Literaria se dieron a conocer, entre otros que no recuerdo ahora, Martínez Sierra, Sancha, Karikato, Ricardo Marín, Santa Ana, Bonilla y Leal da Cámara...» (González Fiol, 1915: 53). Lo cierto es que su nombre consta en la cubierta de las revistas desde el número «Almanaque» hasta el del 18 de marzo, a partir del cual no aparece ningún nombre de director.

La revista publicó, pues, un total de treinta y un números, de los cuales el primero es el más extenso por tratarse de un almanaque (treinta y seis páginas) y los demás constan de dieciocho páginas. En principio, la revista no planificó la salida de números monográficos ordinarios u extraordinarios; sin embargo, con motivo del centenario de Velázquez, se le dedicó el vigésimo segundo número, del 8 de junio de 1899 y se planificó la publicación, de cuya existencia no tengo constancia, de otro dedicado a la ciudad de Granada, ya en el ocaso de la revista.

La Vida Literaria contaba con una nómina de colaboradores fijos. Si bien no publicaban en todos los números, aparecían con frecuencia Gómez Carrillo, Vicente Medina, Martínez Espada, Federico Urales, Lapuya, y otros que enviaban sus textos desde España o desde el extranjero, y cuyas publicaciones respondían a su línea editorial y estética. Al final de los últimos números se hallaba una sección titulada «A vuelta de correo», donde el director respondía de forma irónica y con gran comicidad a los escritos que le iban llegando. El último número, del 10 de agosto de 1899 (donde se dedicaba un apartado especial a la muerte de Emilio Mario) no anunció el cese de la publicación, mantuvo la sección «A vuelta de correo» e incluso anuncia el «Continuará» por entregas de El arte de elegir mujer de Paolo Mantegazza. Tan sólo rogó disculpas por el retraso en la publicación del número, debido a problemas con la impresión del retrato de Emilio Mario.

Lo cierto es que la revista llevaba ya bastantes números en los que su calidad y su interés habían decaído debido, fundamentalmente, a dos factores: el cambio en la línea editorial desde el final de la labor de Benavente como 
director y el paréntesis literario y teatral que suponían los meses de verano, donde se producía un parón en la vida madrileña. Los colaboradores asiduos, cuyos nombres se enmarcan en el canon de la literatura modernista y noventayochista, habían dejado de publicar y tan sólo Gómez Carrillo y Clarín al final, mantenían sus secciones («Día a día: noticias parisienses» $\mathrm{y}$ «Palique»). De los jóvenes escritores, Martínez Sierra colaboraba de vez en cuando, Medina mandaba sus textos murcianos y los demás eran prácticamente todos desconocidos y con una obra de escasa calidad literaria. La Vida Literaria se desarrolló pues en dos etapas distintas: una primera a cargo de Don Jacinto, con una clara línea modernista y rejuvenecedora, y una segunda cuyo director se desconoce y que caminó por derroteros menos renovadores y más cercanos al casticismo.

En esta primera etapa, La Vida Literaria manifiesta claramente su posición modernista y antirregeneracionista. En el segundo número, del 14 de enero de 1899 , se publicó un manifiesto estético donde se planteaba la idea de la muerte del ideal español, que habría causado todos los desastres nacionales, y se abría camino al arte y a la literatura «sin preferencia de nombres ni escuelas; viejos y jóvenes, reaccionarios o liberales, idealistas o positivistas [...] Nos divertiremos con los eternos cuentos de la poesía, con el eterno ritmo de la esperanza y del recuerdo, vaivén continuo en el oleaje de la vida» (La Redacción, 1899: 2). El espíritu de La Vida Literaria era pues, muy amplio; pretendía abarcar un abanico de nombres y escuelas de distintas generaciones, con el fin último de revelar el placer de la belleza del arte y la literatura. De hecho, agrupó nombres de escritores y periodistas ya consagrados como Clarín pero, sobre todo, dio cabida a los jóvenes: el propio Benavente y sus coetáneos (Valle, Unamuno, Baroja, Manuel Machado, Maeztu, Medina, Gómez Carrillo, Darío) y escritores más jóvenes como Martínez Sierra.

El primer número de la revista incluía ya un poema de Darío, «Canción de carnaval», temática carnavalesca que también estaba presente en otros textos de este mismo número, como «El cornetín enamorado. Cuento de carnaval» de Luis Taboada, periodista consagrado en el panorama del humorismo español. El «Almanaque» contaba también con un relato de D'Annunzio: «Parábola de las vírgenes prudentes y las vírgenes locas», asunto que ya había interesado dos años antes al director, Benavente, en su artículo "Vírgenes locas» publicado en El Imparcial el 14 de junio de 1897.

Federico Urales (seudónimo de Joan Montseny) publicó en el segundo número un artículo titulado «Crónica de arte» donde defendía la idea del progreso del arte en esa época de paz, «cosa así como un lujo superfluo que de cuando en cuando se permite el espíritu» (Urales, 1899: 4), y reflexionaba 
sobre el concepto de «decadente», que para él dependía directamente del gusto del público, no de la filosofía estética del escritor.

El propio Benavente, con el seudónimo «Arlequín» (Rubio, 1982) comenzó su sección «Notas de arte» en este número, que ya había surgido en Madrid Cómico en noviembre de 1898 y que aparecería los números cuarto y sexto de La Vida Literaria. Su primer «Notas de arte» se dedicó al Cyrano de Bergerac de Edmond Rostand, y lo defendió como obra de arte sin encasillarlo en una escuela o movimiento determinados, en la misma línea del manifiesto estético de la revista: «Ni retroceso, ni convencionalismo; es el Arte triunfador, el Arte universal, el Arte eterno; el que va enlazando con destellos de luz los nombres de Esquilo, Shakespeare, Molière, Lope de Vega, Schiller, sin cuidarse de géneros ni de escuelas» (Arlequín, 1899a: 6-7). Benavente repite la misma idea en el número seis, donde argumenta la inexistencia de géneros buenos o malos, ni de estéticas literarias mejores que otras; para él, son el trabajo de los autores y su genio lo que diferencian una obra de Arte de otra que no lo es (Arlequín, 1899b: 6).

Además de estos textos de carácter más general, en La Vida Literaria pueden encontrarse verdaderos manifiestos modernistas. Tal es el caso de «Crónica de teatros: la lógica de los caballos» de Pedro Corominas, quien publicó también en la revista su obra Las prisiones imaginarias por entregas. En esta crónica critica, a raíz del estreno de una obra de Sellés -Los caballos- los dramas de tesis, en los que el arte está completamente ausente. Habla de «barroquismo» en escenarios y museos y apela a la juventud para rebelarse «contra tan miserable decadencia» (Corominas, 1899: 2). Corominas critica las ideas de Sellés por alejarse por completo de la realidad: a sus personajes sólo los mueve una lógica, una inteligencia limitada al silogismo, no el corazón.

Muy frecuentes son también los textos a favor del modernismo literario y artístico en lo que atañe al culto a la belleza. La renovación de las letras españolas debiera venir, pues, para los escritores coetáneos, de dos vías: la ruptura con el drama neorromántico y melodramático a favor de otro tipo de lenguaje escénico, y la persecución de la belleza en los textos narrativos y poéticos como fin último, no sujeto a la trama argumental (en relación con el Théâtre de l'Art de Paul Fort). Un ejemplo de ello es el artículo de Urbano González Serrano, dedicado a Campoamor, donde concluye al reflexionar sobre su estilo que, como artista, es más revolucionario que otros por prendarse de lo intuitivo, de lo plástico y del lenguaje por imágenes. Pese a todo esto, en el noveno número de la revista González Serrano niega creer en la regeneración de la sociedad y de las letras, porque el hombre es animal de hábitos y resulta 
complicado que determinadas ideas arraiguen y se asimilen en la vida nueva (González Serrano, 1899: 2).

Los principios modernistas quedan, sobre todo, desarrollados por Enrique Gómez Carrillo en su sección «Día a día: crónicas parisienses», única sección prácticamente fija (comenzó el 4 de febrero en el quinto número) hasta el cierre de la revista (el último artículo pertenece al vigésimo quinto número, del 29 de junio de 1899). En aquellos años, Gómez Carrillo se encontraba entre París y Madrid, y tenía como residencia fija la capital francesa aunque pasara una temporada en la española, donde entabló contacto con multitud de escritores que vivían en la ciudad o fuera de ella, entre ellos Leopoldo Alas $^{1}$. En el decimoquinto número, del 20 de abril, una fotografía de Company muestra la fiesta de bienvenida con que una treintena de personalidades literarias agasajaron a Gómez Carrillo a su llegada a Madrid, y la crónica que la acompaña deja constancia de los propósitos de avance de la revista que allí surgieron (pero que, según se desarrollaron después los hechos, no llegaron a cobrar demasiada forma). El decimonoveno (18 de mayo) anuncia el retorno del guatemalteco a tierras francesas, marcha que no condicionó su producción periodística en La Vida Literaria, pues se mantuvo constante hasta el ocaso de la publicación.

Los «Día a día» de Gómez Carrillo se estructuran siempre de la misma manera: con forma de diario breve, Carrillo anota los hechos más significativos del día (y, sobre todo, de la noche parisina) y las personalidades con las que entabla conversación, algunas frecuentes (como Bonafoux) y otras más esporádicas (como Manuel Machado y otros escritores afamados del momento). Alrededor del barrio de Montmartre, el espíritu bohemio, desenfadado y modernista está presente en todos sus artículos, algunos de los cuales son un alegato a favor de los espectáculos que allí se representaban o de los poetas que en esos días leían sus versos, y otros intentan establecer un puente que una los dos lados de los Pirineos (crónicas sobre la publicación de obras, sobre escritores, sobre actos importantes, etc.).

Ya en su primer texto, Gómez Carrillo ofrece un retrato literario de Alejandro Sawa y reflexiona después sobre este clown, al que califica de «cosmopolita y modernista». Da noticia también de la llegada a París de Pedro Emilio Coll, quien afirma ha revelado a los parisienses la calidad de los escritores modernistas hispanoamericanos. Por último, concluye con la narración, desde el punto de vista del espíritu decadente (Gómez Carrillo, 1899a: 10-11), de la

1. De ello queda constancia en sus cartas, recientemente estudiadas por Jesús Rubio Jiménez, en prensa. 
experiencia vivida en la taberna de las Cuatro Artes con una morena que se inyectaba morfina. En sus artículos elogia a escritores jóvenes como Benavente y Darío, y contradice la opinión de Clarín sobre este último, al que no terminó de comprender. Recuerda también encuentros con los escritores simbolistas franceses: las embriagueces de Verlaine o las primeras lecturas de poemas de Moréas. Especialmente relevante resulta el «Día a día» publicado en el duodécimo número, del 25 de marzo de 1899, donde escribe sobre la literatura de ensueño con motivo de la reciente muerte del poeta Rodenbach. Define el teatro de este autor como el arte de «crear una atmósfera de ensueños silenciosos e influiría en el alma más que en el cerebro, y en la sensibilidad más que en la reflexión. Cuando uno sueña y calla, existe más profundamente que cuando habla y obra» (Gómez Carrillo, 1899c: 6-7). El asunto no representa nada o casi nada y, sin embargo, admira la obra por la atmósfera de fantasmagoría que crea. Este texto se encuadra dentro de toda una corriente de literatura de ensueño que cobraba fuerza en la época, sobre todo a partir de la recepción del teatro de Maurice Maeterlinck, como se verá más adelante.

Así pues, Gómez Carrillo se sitúa dentro del círculo modernista en el que, a pesar de la distinta naturaleza de sus textos, se encuadraba a Benavente, Valle Inclán u otros poetas, con los que presumía de mantener buena relación. Llegó a contar en otro artículo, de hecho, una anécdota que Valle le relatara a su vuelta de Méjico, donde se vio obligado a vivir en una torre rodeado de palomas que le picoteaban la cama.

Sobre la cuestión de la renovación teatral, cobran especial importancia varios artículos, dirigidos a la defensa del teatro benaventino frente al de otros autores y críticos que le censuraban por la ausencia de acción en sus obras. En el decimocuarto número, que Benavente ya no dirigía, M. P. responde a un escritor que ha afirmado que Benavente no es modernista, porque no lleva melenas ni tiene aspecto desaliñado; no ve modernista a un hombre que prefiere el Teatro Guiñol al teatro y que prefiere las obras francesas a las españolas. M. P. comprueba la falta de interés por parte de Benavente en mantener una pose o estética originales, pero esto no le impide erigirse como uno de los estandartes de la renovación dramatúrgica (lo cual es ciertamente discutible, puesto que el aspecto burgués de Benavente en ningún momento fue descuidado o baladí, sino todo lo contrario: respondía a una imagen de dramaturgo similar a los jóvenes franceses, que en su juventud siempre quiso mantener). Lo que, según M. P., diferencia a Benavente de otros literatos es su afán de alentar a muchos escritores más jóvenes, sin clasificarlos o encasillarlos en una u otra escuela estética (M. P., 1899: 2). Ése es el espíritu de La Vida Literaria, tal y como se 
pone de manifiesto en este artículo y como queda demostrado por la nómina de autores que en ella participan.

A pesar de que las obras benaventinas fueron en ocasiones cuestionadas por la crítica, algunas crónicas teatrales de La Vida Literaria ponen de manifiesto que se alzaron como triunfadoras de sus temporadas, especialmente $\mathrm{La}$ comida de las fieras, que fue bautizada como "comedia sin comedia» por los críticos pero entusiasmó al público. El sábado 11 de marzo de 1899, Gómez Carrillo dedicó un apartado de su «Día a día» a Benavente, con motivo del último estreno de una comedia de Maurice Donnay en París. Según parece, la obra no tuvo demasiado éxito, lo que no considera extraño porque el espíritu renovador no tiene demasiada fuerza entre el público. Cree que Rostand y Donnay son dos polos opuestos: el primero un retórico afortunado y el segundo un creador. Gómez Carrillo llega a transcribir, y esto resulta fundamental porque es una de las pocas constancias que de ello tenemos en nuestra lengua, las teorías dramáticas de Donnay y añade que Benavente llevaba tiempo haciendo el mismo tipo de teatro, pues consideraba que, en los diálogos, cualquier frase de más de dos líneas resultaba falsa. Agrupa la nómina de dramaturgos nuevos, entre los que cita a Hervieu, Prévost, Lavedan, De Curel, Germain, Jullien o Becque (Goméz Carrillo, 1899b: 5-6).

Sin embargo, al final de la temporada se lamenta en varios artículos de la abundancia de obras francesas repetitivas, siempre de Sardou o de Dumas, y de la ausencia de nuevos dramaturgos como D'Annunzio, a pesar de que considera que es deber de las compañías italianas importarlo a España. De hecho, en la sección «Revistas teatrales» se reseñan en ocasiones los estrenos de D'Annunzio conjuntamente con los de Ferrari, anterior a éste, o Lavedan como estandartes de la renovación de la escena. Sin embargo, la línea general de pensamiento es pesimista en este asunto. Martínez Espada considera, por ejemplo, que el modernismo no podrá triunfar por el gusto del público y de la crítica, que cuestiona la Teresa de Clarín, el simbolismo de Galdós, a Shakespeare o a Benavente y aplaude a los melodramas, donde el arte queda postergado (Martínez Espada, 1899: 11-12).

La crítica teatral y la defensa del modernismo en las letras y en las artes se reducen ostensiblemente conforme avanza la publicación de la revista y, especialmente, a partir del número en que Jacinto Benavente deja de dirigirla. Ya en sus últimos números, estos textos permanecen ausentes, probablemente debido a la temporada en que se publicaron, durante los meses veraniegos de cierre teatral y sin apenas espectáculos, salvo variedades u otras obras de menor importancia que no merecían la pena, según los críticos, de ser comentadas. 
De especial interés resulta la publicación, en el número cuarto de la revista, del 28 de enero de 1899, del cartel del inicio del Teatro Artístico de Benavente, que había diseñado Santiago Rusiñol y cuya primera obra iba a ser Interior de Maurice Maeterlinck. Este cartel establece una conexión directa entre Madrid y Barcelona, entre los círculos modernistas de la capital española, especialmente encarnados en las figuras de Benavente, Valle y los Martínez Sierra y el catalán, el cual, según Eduard Valentí, se encontraba en un callejón sin salida, pues el radicalismo de sus representantes y su separación de la sociedad habían provocado la reacción de sus opositores, que no consiguió fraguar dada la presencia de otros escritores, como Rusiñol, que concebían el modernismo en términos menos conflictivos (Valentí, 1973: 302).

Gómez Carrillo reseñó la publicación de este cartel dos meses después, en el citado artículo del 25 de marzo. En él explica que ha visto el cartel de Interior en casa de un vendedor de carteles artísticos y cree que en Madrid no habrá gustado precisamente por su condición de artístico: el público aplaude en Cyrano, de manera que la dirección del Teatro Artístico habría conseguido mayores beneficios de taquilla anunciando Pélleas et Mélisande. Sin embargo, en su opinión Interior es la que más gráficamente ilustra el alma del poeta, poeta del silencio. Transcribe después las siguientes líneas de Maeterlinck sobre sus teorías dramáticas:

¿Qué es el verdadero teatro sino la vida casi inmóvil? En general debe suprimirse toda acción hasta la psicológica, que es muy superior a la otra, con objeto de no dejar subsistir sino el interés que despierta la situación del hombre en el universo. No vivimos entre bárbaros y el ser humano no se mueve en medio de pasiones entre pasiones visibles que son las peores. Tenemos tiempo para verle cuando descansa y sueña. No busquemos un instante de su existencia sino toda su existencia. Las leyes venerables son discretas, lentas, silenciosas y no se perciben sino en el crepúsculo y en el recogimiento de las horas tranquilas (Gómez Carrillo, 1899c: 6-7).

Este elogio del teatro de ensueño y de la literatura simbolista se traduce también en La Vida Literaria a través de los textos de creación. A pesar de tratarse de una publicación de carácter misceláneo en la naturaleza de sus textos (cómicos, críticos, modernistas, burgueses, etc.), la revista mantiene una línea constante de inclusión de textos de influencia maeterlinckiana, por un lado, y de Rubén Darío por otro. Gregorio Martínez Sierra fue uno de los colaboradores asiduos, pues comenzó a publicar desde el primer número hasta el vigésimo octavo, del 20 de julio de 1899. El primer texto, «La siega», es un poema en decasílabos sobre el tema «juventud, amor, vida y trabajo», en la línea de otro titulado « $i \ldots . . . . .$. ? » sobre las ideas del progreso, que juzga dormidas. «Lluvia de notas (sensaciones de la música de Amadeo Vives)»(22/VI/1899) 
relaciona la música con los estados del alma y con sinestesias de vista y oído, y se configura como uno de los artículos de carácter modernista más representativos de la revista.

No obstante, el tema más frecuente en los textos de M. Sierra publicados en La Vida Literaria es el del alma del poeta, cómo debe traducirse en su poesía y cuál es su labor artística. Tal es el caso de «Introducción a un poema: fragmentos», publicado en el número tercero (21///1899):

¿Dónde fue? ¿Cuándo fue? ¡Y eso qué importa!

Para cantar dolores y alegrías,

¿interesan ni tiempos ni lugares?

Espacios infinitos, ¿os define ni os mide la radiante y clara estrella que recorre fugaz vuestros senderos, luciente estela tras de sí dejando? [...] lo que interesa al alma del poeta, el soplo inspirador y misterioso que ha de agitar las cuerdas de su lira, conmoviendo a su son las fibras todas que se sienten esparcidas por el mundo, es el eco profundo y sostenido de la pasión humana que, saliendo del pecho mismo que se agitó potente obliga a palpitar de angustia o dicha a todos los amantes corazones capaces de abrigar aquel latido con ternura de hermanos cariñosos [...] (Martínez Sierra, 1899a: 7).

Y de «Brindis» (4/III/1899), sobre su esfuerzo como poeta y sobre el aliento que le infunden otros, como J. Ruiz Castillo, a quien va dedicado:

-a ti que eres artista y que en mí crees-

para brindarte mi primer batalla... [...]

Si la amarga derrota me acomete

Espérame también que iré a tu lado [...]

¡Prestar fuerzas y alientos a un vencido...!

¿Qué mejor galardón para un poeta? (Martínez Sierra, 1899c: 11).

«Almas muertas y almas vivas», de Federico Urales, sigue la línea de «Introducción a un poema»; se trata en este caso de un poema en prosa también sobre el alma del artista: «Ama y espera, artista; si así lo haces las espinas en flores se tornarán, el carbón en diamante, en luz las negruras, en ángeles los hombres. Trabaja y besa: tu obra es inmortal. Repara cómo te acaricia el céfiro» (Urales, 1899b: 4).

El decadentismo está presente en los textos de Alberto Ghiraldo, escritor argentino de ideario anarquista nacido en 1875 y fallecido en 1946. Publicó 
un buen número de artículos en La Vida Literaria desde el quinto número (4/II/1899), todos ellos con el tema de la muerte, en la línea maeterlinckiana. «De la Noche» (4/II/1899) es un ejemplo: se trata de cinco coplas en versos dodecasílabos sobre el misterio como sentimiento implacable y cercano a la muerte: « $i \mathrm{Oh}$, tú siempre flotando en las cosas, / inmenso, implacable, doliente Misterio / fatal, dominando las vidas, terrible; / tú siempre en las sombras, tú siempre en los vientos» (Ghiraldo, 1899a: 4). Ghiraldo continuó este poema en el séptimo número (18/II/1899), en este caso inspirado en la mirada enigmática de una mujer, que se desconoce si infunde muerte o locura: «Hay la ficción de las visiones trágicas / en la pupila atónica y adusta; / el gesto doloroso del que alienta / camino de la Muerte o la Locura» (Ghiraldo, 1899b: 3). En «París» y «De la naturaleza» el temor a la muerte no se manifiesta, ya que se trata de dos cantos modernistas de temática espacial muy diferentes a los anteriores.

No obstante, la literatura de ensueño no sólo queda representada en La Vida Literaria a través de los textos de Ghiraldo. Otros escritores menos conocidos cultivaron esta estética a lo largo de toda la revista. Resulta especialmente importante la propia evolución de La Vida Literaria en este sentido, pues se establece una progresión claramente marcada por la abundancia de artículos de carácter modernista en torno al carnaval, la naturaleza o el alma del poeta en los primeros números, y más cercanos a la literatura de ensueño conforme avanza la publicación. Dos de la primera etapa son los «Apuntes» de Juan B. Carlo (4/II/1899 y 4/III/1899), textos narrativos pero con carácter poético sobre la muerte en el momento de acostarse, sobre la confusión entre ésta y la ensoñación y sobre los instantes anteriores a la llegada de un mal recuerdo, respectivamente. «Nocturno», de Camilo Bargiela (11/III/1899) mantiene la temática de la noche ligada al asunto amoroso.

A partir del decimoséptimo número (4/V/1899) se van sucediendo los textos de ensueño, muchos de ellos en la línea de los citados «Apuntes», es decir, centrados en los segundos previos al sueño. Tal es el caso de «Dormido y despierto» de N. Díaz de Escovar, donde esos instantes se relacionan con el sentimiento amoroso igualando a la imagen de la amada, que permanece impávida, fija en los dos planos de la realidad. Por su parte, «La toga», de Alfredo F. Feijoo (11/V/1899), ofrece una perspectiva distinta: la somnolencia del protagonista causada por el traquetreo del tren le lleva a soñar con la toga que se encuentra enfrente, la cual termina cobrando vida y extinguiéndose al despertar. Lo que era sueño terrible de noche se convierte en alegría inmensa de día. 
El cuento de Zamacois «Pesadilla» (25/V/1899), inserto en la sección «Cuentos españoles» que se comenzó a publicar en la segunda etapa de la revista, narra el sueño de Eva, mujer hermosa que había encendido tantas pasiones que soñaba que se disputaba con otras damas el corazón de un hombre, pero ella se veía invencible por su belleza. Vislumbra a muchas mujeres iguales, las Horas, que afirman ser las omnipotentes motoras del mundo, que la afearán y que terminarán acabando con su vida. Eva, horrorizada, despierta y se mira al espejo, pensando que envejecer no importa porque es joven y hermosa (Zamacois, 1899: 5-6). De nuevo se traduce en este cuento el sentimiento opuesto relacionado con cada parte del día: alegría/día y horror/noche. «Ensueños», de Alberto Lozano, publicado en el último número de la revista, presenta un matiz con respecto al resto de artículos de ensueño anteriores: en este caso se ocupa de los momentos simultáneos y posteriores a la ensoñación, donde un amante enfermo se funde en un beso con su amada, quien le pide que despierte y luche por conservar su vida (Lozano, 1899: 7). El tema del sueño está, pues, ligado íntimamente a la muerte y adquiere, en general, un tono dramático en todos estos textos de carácter simbolista.

«El lago», de Alberto L. Arguello (18/III/1899), no versa específicamente sobre la muerte, pero sí ofrece otro típico elemento maeterlinckiano: el lago como oposición entre luz y oscuridad, reposo por fuera y penumbra por dentro, y su extensión al resto del universo (similar a la concepción de la fuente en Pelléas et Mélisande).

Sobre el tema del carnaval, cabe destacar dos textos, «Canción de carnaval» de Rubén Darío, publicada en el primer número de la revista, y «Carnaval», de Gregorio Martínez Sierra, perteneciente al sexto número, del 11 de febrero de 1899. La tradición del carnaval, relacionada con la commedia dell'arte, era un tema de gran actualidad en la España de Fin de Siglo. Benavente utilizó la relación Arlequín-Colombina en sus publicaciones en la revista Juan Rana y muchos de sus caracteres en Los intereses creados. Sin embargo, y dejando este tipo de obras a las que la crítica ya ha atendido, Benavente ensaya también un relato basado en la concepción francesa del personaje de Pierrot: $L a$ blancura de Pierrot, que recogerá en su Teatro fantástico. Se desarrollan así dos vías: la de la utilización de personajes de la commedia desde el punto de vista cómico-caricaturesco y la de la dramatización de algunos caracteres. David George ya observó la continua aparición de personajes carnavalescos en el cambio de siglo, no ceñida a la época del carnaval sino sobre todo presente en las publicaciones periódicas, pues estaba de moda tanto en obras de carácter más popular como en las que eran consideradas «alta cultura» (George, 1995: 
28). Rubén Darío mantiene la visión carnavalesca de los personajes, alegre, fresca y danzarina:

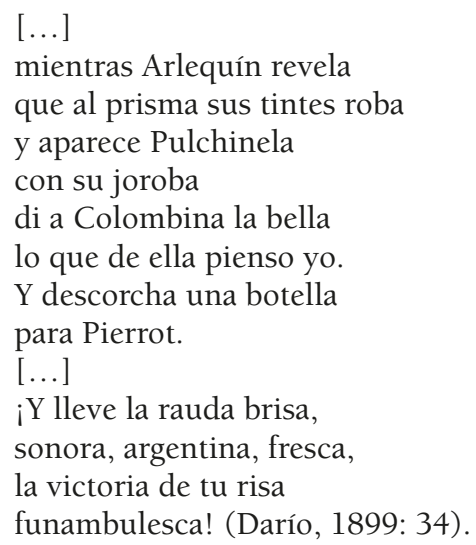

El artículo de Martínez Sierra es diferente: plantea la tensión entre la alegría del Carnaval y la tristeza tras su final, y todo el texto mantiene el tono trágico. Sin embargo, los personajes de Pierrot y Colombina no siguen el cambio de la felicidad a la amargura, sino que desaparecen cuando lo hace el carnaval porque pertenecen únicamente a él, y no pueden dramatizarse: «Expiró la noche tercera; desaparecieron, como por magia, las risueñas figuras de Pierrot y Colombina; rompióse el encanto... En el suelo, revueltos con el fango, yacen los restos de la fiesta: flores marchitas, cintas ajadas, girones de disfraces, caretas pisoteadas...» (Martínez Sierra, 1899b: 13). A continuación del poema de Martínez Sierra se encuentra un soneto de Bernardo G. de Candamo, introducido por un verso de Verlaine, con la Locura carnavalesca como tema común a ambos:

La fiesta es en tu honor, viejo que evocas
de la Locura los palacios caídos.
Oye a la juventud que tus oídos
quiere alegrar con canciones locas.
Vestidos de colores, ricas tocas
más hermosas aún que los vestidos;
canallescas canciones, alaridos,
y la sonrisa en las bermejas bocas.
Llega la noche; sigue de la fiesta
la alegre gritería; en dulce orquesta
sus coplas a entonar vuelve la Tuna.
Citas se dan los hombres con mujeres,
y, antorcha de los báquicos placeres,
muestra su rostro de Pierrot la Luna (De Candamo, 1899: 13). 
Además de los artículos modernistas, La Vida Literaria ofrece al lector otra serie de escritos de carácter más casticista, con firma variopinta, pues la nómina de escritores cercanos al modernismo era más reducida que la realista o la regionalista. Tal es el caso del murciano Vicente Medina, quien publicó sus conocidos relatos de habla popular, especialmente en la segunda etapa, con el nombre de «Aires murcianos» o de la antes citada sección "Cuentos españoles», donde aparecieron (además de algunos miembros de la llamada Generación del 98) escritores como Nicolás de Leyva, Alfredo F. Feijoo, Camilio Bargiela, el crítico Manuel Bueno, José Ignacio de Alberti, E. de Lustonó, Juan P. de Zulueta (que había colaborado en más ocasiones) o Adolfo Luna, entre otros.

Lo cierto es que, desde que Benavente deja la dirección de la revista, aproximadamente en la mitad de su trayectoria, la línea editorial de la revista comienza a caminar hacia lo regionalista, casticista y popular de una manera más clara que en la anterior donde, especialmente en los primeros números, se había orientado hacia la renovación de las letras españolas a través del europeísmo. De menor interés resulta este segundo itinerario de la revista, cuyos artículos adquieren un carácter misceláneo e incluso pierden calidad literaria; sería necesario un estudio pormenorizado en relación con la literatura popular de la época y con el género chico.

En la primera etapa tuvieron cabida, pues, textos de distintas nacionalidades y en distintos idiomas. Especialmente relevante parece la sección «Letras extranjeras» que se publicó en el número almanaque y se mantuvo, aunque de manera esporádica, a lo largo de la vida de la revista. En dicha sección se pueden encontrar dos poemas portugueses (traducidos literalmente del original) de Eugenio de Castro y del Marqués de Figueroa, respectivamente; un cuento alemán de Volkmann, dos poemas de Hood y Shelley (cuya inserción decidió probablemente Benavente, pues citaba continuamente a Shelley e incluso tradujo uno de Hood, "La camisa», en la revista Germinal dos años antes); una leyenda rusa de R. Peichersal, una traducción de Paul Hervieu (otro de los modelos dramáticos de las comedias burguesas benaventinas) y varios catalanes.

En esta primera época de la revista, de carácter europeísta, destaca también de manera notoria la presencia de textos de Friedrich Nietzsche, quien sin embargo desaparece según avanza el número de publicaciones. A Benavente se le relacionó con Nietzsche sobre todo a través de la protagonista de La noche del sábado, Imperia, como defendieron Gonzalo Sobejano (1967: 248) o Pedro Laín Entralgo en una conferencia que se conserva en la BNE. Sobre la presencia de Nietzsche en el modernismo español, Sobejano considera que 
este grupo de escritores «sienten como mayores focos de atracción en el pensamiento de Nietzsche la exaltación dionisíaca de la vida y la justificación estética del mundo» (Sobejano, 1967: 195), mientras que los miembros de la que él acepta como Generación del 98 «se fijan tanto o más que en esto en los pilares del evangelio de Zaratustra: muerte de Dios, voluntad de poder, eterno retorno, anhelo de superhombre» (Sobejano, 1967: 195). En La Vida Literaria, la presencia de los miembros del 98 (Valle, Baroja, Unamuno -con escritos de carácter lingüístico en líneas generales- o Maeztu) es esporádica pero relevante, y sería necesario dedicar un estudio a su relación con las distintas etapas de la revista, de igual manera que los «Palique» de Clarín, quien empezó publicando textos de carácter misceláneo y recuperó la sección del Madrid Cómico hacia el final de la revista (desde el vigésimo sexto número, 6/VII/1899, hasta el último, con un total de seis «Palique»). La razón que explica su regreso a la revista aparece en el vigésimo sexto número:

Con mucho gusto vuelvo a escribir asiduamente en La Vida Literaria, primero porque es el sucesor de mi querido Madrid Cómico, después porque aquí predomina el elemento joven; y yo, digan lo que quieran mis enemigos literarios, soy muy amigo de la juventud. No le gustan nada ni la desfachatez ni los escritos indecorosos ni los envidiosos, cree que de esto está libre la revista (Alas, 1899: 2).

Así pues Benavente, como director de La Vida Literaria, consideraba un motor necesario para la renovación de las letras la ampliación de las miras literarias a los nuevos moldes europeos. Este ideario se va perdiendo, conforme avanza la publicación, hacia artículos cada vez más españoles y menos renovadores, probablemente a causa de la dificultad para encontrar colaboradores y por el gusto del público, que encontraba más entretenidos estos textos que los de autores o estilos que les eran desconocidos.

La presencia de Benavente, no obstante, fue constante en la revista. Además de los artículos citados que firmaba como Arlequín, publicó otros («Vaticinios para el año 1899» en el número almanaque, «Armando Palacio Valdés», «Leyes suntuarias»y «Para terminar» ${ }^{2}$ ), en general de crítica teatral, incluso

2. Este artículo responde a una polémica surgida a partir de una entrevista publicada en el número trece de La Vida Literaria con el título «Los pintores de provincias: José Garnelo», por Luis de Lara. En el número siguiente, del 21/1/1899, p. 15, se aclararon una serie de afirmaciones biográficas de la entrevista que no eran correctas, y el Sr. Garnelo acusó en Blanco y Negro a Benavente de ser el autor de la entrevista y de inventar parte del texto. D. Jacinto contestó que el pintor mismo facilitó los clichés de los cuadros que ilustraban el texto y que las frases que allí se transcribieron fueron pronunciadas por él. Respeta las opiniones de todos los críticos (aunque le sean desfavorables) pero no que después las nieguen, y lo critica como pintor y como persona. 
en el primer número su drama El criado de Don Juan. No faltaron, tampoco, escritores que trataron de seguir su estética dramática de plasmación de diálogos y conversaciones espontáneas, tanto en la escena como en los escritos breves publicados en la prensa. Tal es el caso de «La playa... de recoletos. Conversaciones al oído», de Agustín García Cano (vigésimo noveno número, 27/VII/1899), en la línea de los que Benavente había publicado antes en El Globo, Madrid Cómico o Juan Rana y que en 1874 había realizado Pedro Antonio de Alarcón (recoger en breves líneas, pinceladas, lo que se escucha por las calles o por distintos lugares). Gregorio Martínez Sierra publicó también en el número duodécimo (25/III/1899) «Una carta de mujer», tomando como modelo las que el dramaturgo madrileño había publicado en la prensa desde sus primeros pasos como escritor.

La Vida Literaria se configura así como uno de los intentos de los jóvenes escritores, capitaneados por Jacinto Benavente, de renovación de las letras españolas a través de dos vías: el modernismo y ampliación de horizontes hacia la literatura europea. En ella abundan escritos críticos sobre el anquilosamiento teatral y sobre la necesidad de devolver a la creación escrita su espíritu artístico, la belleza en las formas y la metáfora y la sinestesia en el contenido. Con la literatura de ensueño como una de las líneas creativas más importantes, y con la inclusión de textos extranjeros (europeos e hispanoamericanos), La Vida Literaria amplió la nómina de autores a algunos de los que hoy forman parte del canon modernista y a otros más conservadores en su escritura, pero todos pertenecientes a una misma generación. Sin embargo, la propia evolución de la revista la condujo hacia la pérdida progresiva de este carácter renovador, lo que acarrearía su fin en agosto de 1899. Treinta y un números demuestran la oposición entre el público y los literatos sobre debates estéticos y sobre las distintas corrientes que convivían en el momento, incompatibles en sus planteamientos pero enmarcadas dentro de un soporte común: la prensa periódica.

\section{Bibliografía citada}

Botrel, Jean-François, «Clarín» y el Madrid Cómico: historia de una colaboración (1883-1901), Alicante, Biblioteca Virtual Miguel de Cervantes, 2003.

GEORGE, David, The history of de commedia dell'arte in modern hispanic literature with special attention to the work of García Lorca, Nueva York, Lewiston, 1995.

GonZÁlez Fiol, Enrique, Domadores del éxito: confesiones de su vida y de su obra, Madrid, Sociedad Editorial de España, 1915.

RUBio JimÉNEZ, Jesús, «Colaboraciones de Benavente en la prensa madrileña: 1890-1900», Cuadernos Bibliográficos, 44 (1982), pp. 135-151. 
SERRANO, Javier y Amparo de Juan, (coords.), Literatura hispánica y prensa periódica (1875-1931): actas del congreso internacional, Lugo, 25-28 de noviembre de 2008, coord. por Javier Serrano y Amparo de Juan, 2009.

SobejAno, Gonzalo, Nietzsche en España. 1890-1970, Madrid, Gredos, 1967.

VALENTí, Eduardo, El primer modernismo literario catalán y sus fundamentos ideológicos, Barcelona, Ariel, 1973.

Versteeg, Margot, «Jacinto Benavente, director de Madrid Cómico», en Literatura hispánica y prensa periódica (1875-1931): actas del congreso internacional, Amparo de Juan y Javier Serrano (coords.), Lugo, 25-28 de noviembre de 2008 (2009), pp. 425-438.

\section{Artículos de La Vida Literaria citados}

AlAS, «Clarín», Leopoldo, «Palique», La Vida Literaria, 26 (6/VII/1899) p. 2.

ARLEQuín, «Notas de arte: Cyrano de Bergerac», La Vida Literaria, 2 (14/I/1899a), pp. 6-7.

ArLeQuín, «Notas de Arte», La Vida Literaria, 6 (11/II/1899b), p. 6.

Corominas, Pedro, «Crónica de teatros: la lógica de los caballos», La Vida Literaria, 5 (4/II/1899), p. 2.

DARíO, Rubén, «Canción de carnaval», La Vida Literaria, 1 (7/I/1899) p. 34.

DE CANDAMO, Bernardo, «Rimas a Carnaval», La Vida Literaria, 6 (11/II/1899), p. 13.

GHIRALDO, Alberto, «De la Noche», La Vida Literaria, 5 (4/II/1899a), p. 4.

GHIRALDO, Alberto, «De la Noche», La Vida Literaria, 7 (18/II/1899b), p. 3.

GÓMEZ CARRILlo, Enrique, «Día a día: notas parisienses», La Vida Literaria, 5 (4/ II/1899a), pp. 10-11.

Gómez CARILlo, Enrique, «Día a día», La Vida Literaria, 10 (11/III/1899b), pp. 5-6.

Gómez CARrillo, Enrique, «Día por día», La Vida Literaria, 12 (25/III/1899c), pp. 6-7.

GONZÁLEZ SERRANO, Urbano, «¿Regeneración?», La Vida Literaria, 9 (4/III/1899), p. 2.

La Redacción, «Vida literaria: introducción», La Vida Literaria, 2 (14/I/1899), p. 2.

LOZANO, Alberto, «Ensueños», La Vida Literaria, 31 (10/VIII/1899), p. 7.

M. P., «Benavente», La Vida Literaria, 14 (13/IV/1899), p. 2.

Martínez Espada, Manuel, «Crónica teatral. Los dos pilletes, melodrama de Decourcelle», La Vida Literaria, 25 (29/VI/1899), pp. 11-12.

MARTínEZ SiERRA, Gregorio, «Introducción a un poema: fragmentos», La Vida Literaria, 3 (21/I/1899a), p. 7.

MARTínEZ SiERRA, Gregorio, «Carnaval», La Vida Literaria, 6 (11/II/1899b), p. 13. 
MARTínez SierRA, Gregorio, «Brindis», La Vida Literaria, 9 (4/III/1899c), p. 11.

URALES, Federico, «Crónica de arte», La Vida Literaria, 2 (14/I/1899a), p. 4.

URALES, Federico, «Almas muertas y almas vivas», La Vida Literaria, 4 (28/I/1899b), p. 4.

ZAMACOIS, Eduardo, «Pesadilla», La Vida Literaria, 20 (25/V/1899), pp. 5-6.

Fecha de recepción: 10/04/2014

Fecha de aceptación: 01/09/2014 